\title{
Use of internal documents to investigate a tobacco company's strategies to market snus in the United States
}

\author{
Joshua U. Rhee', Jamilla Y. Abugazia', Yan Marco E. Dela Cruz', David S. Timberlake'
}

\begin{abstract}
INTRODUCTION Prior studies indicate that cigarette manufacturers have been interested for decades in developing a smokeless tobacco (SLT) product for smokers and non-users of SLT. The current study aims to assess a tobacco company's use of novel marketing strategies and intent to promote snus in the US as either a replacement or situational substitute for the cigarette.

METHODS A Boolean search string was used to search R. J. Reynolds' (RJR) Records in UCSF's Truth Tobacco Industry Documents Library. A total of 358 documents, from 2005-2009, met our initial search criteria and were selected for their relevance to the marketing of Camel Snus. A content analysis was subsequently conducted using the Framework Method to identify themes and strategies for promoting Camel Snus.

RESULTS Four major themes about Camel Snus emerged from the documents: 1) promotion by third parties including retailers, snus ambassadors and secret shoppers, 2) expansion of the target population of SLT users to include female smokers and dual users of cigarettes and SLT, 3) emphasis on the difference between Camel Snus and other SLT, and 4) a shift from promoting the practical uses of Camel Snus to using emotional messages conveying freedom.

ConcLusions The findings align with other studies suggesting that RJR intended to market snus to non-users of SLT. The findings also reveal that RJR employed creative marketing strategies (e.g. snus ambassadors) and may have intended to promote snus as a situational substitute for the cigarette, as evidenced by the company's recruitment of dual tobacco users.
\end{abstract}

\section{AFFILIATION}

1 Department of Population Health and Disease Prevention, College of Health Sciences, University of California, Irvine, United States

\section{CORRESPONDENCE TO}

David S. Timberlake. Department of Population Health and Disease Prevention, College of Health Sciences, University of California, Irvine, Anteater Instruction \& Research Building, Irvine, CA 92697, United States. E-mail: dtimberl@uci.edu

\section{KEYWORDS}

marketing strategies, harm reduction, snus, internal documents, poly-use of tobacco

Received: 7 October 2020 Revised: 18 December 2020

Accepted: 18 December 2020

\section{INTRODUCTION}

R. J. Reynolds' (RJR) strong interest in non-cigarette tobacco products dates back to 1978 when it developed the Specialty Tobacco Products Division ${ }^{1}$. To attract a broader consumer base, cigarette manufacturers needed to develop a more appealing and novicefriendly smokeless tobacco (SLT) product. The advent of packaging moist snuff in a 'tea-like' pouch was one such advancement that prevented tobacco displacement in the mouth and controlled the level of nicotine exposure, particularly for an inexperienced user. In 2006, RJR test-marketed their newest pouchlike snus product Camel Snus into the US SLT market.
The initial campaign to promote Camel Snus by using Swedish themes and marketing events at nightclubs (e.g. driving limousines to nightclubs) may have been an attempt to appeal to individuals who do not identify with SLT ${ }^{1}$. Original advertisements of Camel Snus in the US were primarily oriented to cigarette smokers with references to an urban lifestyle (e.g. enjoy taxicabs, subways and bar-hopping $)^{2}$. The content of these advertisements differed considerably from the predominant stereotype of SLT users: White males who reside in rural USA. Most advertisements alluded to the benefit of not requiring spitting $(52.5 \%)$ and some were published in female oriented magazines ${ }^{2}$. 
Examinations of tobacco industry documents have revealed that the attempt to market moist snuff to younger and more sophisticated people occurred long before the national debut of Camel Snus in $2009^{1,3,4}$. Changes in the social acceptability of cigarette smoking and the looming smokefree policies were the impetus for cigarette manufacturers' investment in the consumer research and marketing development of SLT products ${ }^{3}$. The pouched snuff Skoal Bandits, the predecessor to Camel Snus, was successful in capturing a significant share of the SLT market compared to other SLT products $^{4}$. As reported by Hendlin et al. ${ }^{4}$, initial marketing research conducted by the U.S. Smokeless Tobacco Company (USST) indicated that among smokers who tried Skoal Bandits, the majority wanted to use the product as either a cigarette replacement $(53.9 \%)$ or situational substitute $(42.6 \%)$. A cigarette replacement is defined as a tobacco product used to help quit smoking, whereas a situational substitute is a concurrent tobacco product used instead of smoking due to restrictions (i.e. smoke-free policies). Despite smokers showing interest in using SLT and USST's efforts to reach 'micro markets' (e.g. Hispanics, African Americans), Skoal Bandits never made a significant inroad to demographic groups beyond the company's traditional consumer base ${ }^{4}$. Similarly, the marketing of snus, which was directed more to cigarette smokers than traditional SLT users ${ }^{5}$, had initially generated interest among male smokers from two US cities $(29.9 \% \text { tried it })^{6}$; but, few proceeded to adopt use of the product $(4.2 \%)$. This begs the question of whether RJR developed a new strategy to market Camel Snus or 'mirrored the historical advertising of Skoal Bandits', as concluded by Hendlin et al. .

Content analyses of advertisements are useful for identifying the intended audience of Camel Snus (i.e. cigarette smokers) $)^{2,7}$. Yet, these approaches are limited because the intended use of snus in the advertising, as either a permanent replacement or situational substitute for the cigarette, is ambiguous. The ambiguity may be attributed to the 2009 Tobacco Control Act's (TCA) restrictions on making harm reduction claims (i.e. cigarette replacement) or RJR's concealment of its intent to market snus as a situational substitute. The latter is particularly concerning because the message promotes dual use (concurrent use of both cigarettes and snus on a regular basis), a topic often neglected among pro-snus activists ${ }^{1}$. Dual usage has been shown to impede smoking cessation ${ }^{8}$, exacerbate nicotine dependence ${ }^{9,10}$ and possibly increase the risk for oral and pharyngeal cancers ${ }^{11}$. An examination of RJR's internal documents in the current study aims to assess the intended use of Camel Snus and determine whether the company has adopted novel marketing strategies or borrowed strategies from past campaigns (e.g. Skoal Bandits).

\section{METHODS}

\section{Selection of documents}

A Boolean search string was used to search for RJR Records in UCSF's Truth Tobacco Industry Documents Library (https://www.industrydocuments.ucsf.edu/ tobacco/) relating to the marketing of Camel Snus from 2005-2009. The Boolean search string included the following terms: 1) ASU30 (Adult SLT users $\leq 30$ years), 2) ATCU50 (Adult Tobacco Consumers $\leq 50$ years), 3) ATO30 (Adult Tobacco users $\geq 30$ years), 4) SNUS, 5) HoReCa (Hotel Restaurant Café), 6) Secret Shopper, 7) SNUS Ambassadors, 8) SNUS Health, and 9) SNUS Total Tobacco. The year 2005 was chosen because it corresponds to the first internal document containing relevant information about the marketing of Camel Snus. The year 2009 was chosen because it captures the marketing that led up to the national debut of Camel Snus and passage of the TCA that imposed marketing restrictions on commercial tobacco products. This time-frame captures information on novel marketing strategies using different medium channels and their adaptation to the TCA's new laws. Snowball sampling ${ }^{12}$ was employed to identify additional documents pertaining to the marketing of Camel Snus. After the exclusion of unrelated documents, 348 articles were analyzed to develop themes.

\section{Analysis using the framework method}

This study used the proposed guidelines of the framework method ${ }^{13}$ to develop themes related to the marketing of Camel Snus. First, codes were first developed using a deductive approached based on existing literature on the marketing of snus. For example, the following code 'can use snus where smoking is prohibited' was created before data 
collection through prior readings of recent literature ${ }^{6}$. Second, an inductive approach was used to develop codes during data analysis. For example, the following code 'child resistant packaging for Camel Snus tins' was created while analyzing the internal documents ${ }^{14}$. Third, an analytical framework was created by comparing coders' labels and grouping the codes into categories. Fourth, themes were created through the interpretation of the data. The final analytical framework, which consisted of four categories (Demographic groups, Selling points of Camel Snus, Marketing Tactics, and Harm Reduction) and 49 codes, was developed over the course of several months. The codes from all three coders were compared for assessing inter-rater reliability ${ }^{15}$ (Cohen's Kappa
0.612-0.661); the coding discrepancies were subsequently resolved through group discussions. The software program Atlas.ti 8.4 Windows ${ }^{16}$ was used for storing, coding, and organizing the data according to the analytical framework.

\section{RESULTS \\ Using third parties to market snus}

The most noticeable marketing tactic employed by RJR was using third parties to market Camel Snus, notably 'Snus Ambassadors' who engaged with the public at bars and clubs (Table 1). The young adults at these venues were frequently the target of snus ambassadors as evidenced by the quote '... ATU30 (Adult Tobacco users $\leq 30$ ) are significantly more likely

\section{Table 1. Generated themes with relevant quotes}

\begin{tabular}{|c|c|}
\hline Using third parties to market snus & Relevant quotes \\
\hline Snus ambassadors & $\begin{array}{l}\text { 'SNUS Ambassadors and Retail Intercept Reps serve to engage and interact with smokers } \\
\text { in a dialogue aimed at creating informed awareness, trial, and acceptance of Camel } \\
\text { SNUS.'17 }\end{array}$ \\
\hline Retail clerks & $\begin{array}{l}\text { 'We must strive to have all retailers hand out CAMEL SNUS "give ones" to all adult } \\
\text { tobacco consumers ... We must educate those retailers who are willing and able to } \\
\text { communicate with adult tobacco consumers. }{ }^{\prime 42}\end{array}$ \\
\hline Secret shoppers & $\begin{array}{l}\text {... to conduct secret shopper missions and then rewarding clerks and store managers } \\
(\$ 5.00 \text { and } \$ 10.00 \text { gift cards) for their knowledge of Snus and their willingness and } \\
\text { capability to engage consumers on our behalf.'22 }\end{array}$ \\
\hline \multicolumn{2}{|l|}{ Expanding from primary target population } \\
\hline Female ATU \& ASU30 & 'Group Engagement and Extended Reach [for] Balanced Male/Female and ATU30/AT030'43 \\
\hline Latinx & $\begin{array}{l}\text { 'I recently finalized a series of informal dinners with Hispanic ATU, and this is a brief } \\
\text { report that I made about the findings ...' }\end{array}$ \\
\hline Dual users & 'We will tactically leverage the dual users ...'24 \\
\hline \multicolumn{2}{|l|}{ Differentiating snus from SLT } \\
\hline Swedish origin & 'Swedish Origin - Modern, clean, and Euro-vibe'27 \\
\hline Spitless & 'Discrete way to enjoy tobacco for when you can't smoke!'45 \\
\hline Different from moist snuff/pasteurized & 'Camel SNUS is not like US moist snuff. US moist snuff is fermented ...' \\
\hline Sold and enjoyed cold & 'Elevate product point of difference, i.e. refrigerated, fresh taste.'27 \\
\hline \multicolumn{2}{|l|}{ Marketing from practical to emotional } \\
\hline Shift in marketing messaging & $\begin{array}{l}\text { 'Dimensionalize Camel SNUS platform from functional to more emotional with Camel } \\
\text { voice ... Shift from convenience to the freedom to make any when I can't smoke moments } \\
\text { more pleasurable ...' }\end{array}$ \\
\hline Emotional needs & $\begin{array}{l}\text { 'Consideration and Trial are critical bottlenecks among ATC Females. Opportunity is } \\
\text { evident however, in the behavioral profile similarity between Female and Male users. } \\
\text { Cultivate their interest with a tone and messages more relevant to their lifestyles and } \\
\text { emotional needs (perhaps inclusion, acceptance, security).'25 }\end{array}$ \\
\hline Novel way to enjoy tobacco & $\begin{array}{l}\text { 'Free to have that (self-esteem, confidence, socialness that cigarettes provide you) } \\
\text { but now you have this emotional benefit all the time ... Camel Snus breaks away from } \\
\text { convention by bringing me a new way to enjoy tobacco that gives me more benefits than } \\
\text { what exists today.30 }\end{array}$ \\
\hline
\end{tabular}


than ATO30 (Adult Tobacco users $\geq 30$ ) to mention receiving multiple free samples likely influenced by the Ambassador Program...' ${ }^{17}$. As a third party, snus ambassadors worked closely with RJR representatives, but were not employees of RJR. Ambassadors were tasked with creating a dialogue with smokers in an effort to increase smokers' awareness, initiation and acceptance of Camel Snus. RJR recognized the receptivity of poly-tobacco users to Camel Snus, and hence, suggested that such users serve as snus ambassadors who '... are prime candidates for creating an advocacy group' ${ }^{\prime 18}$.

RJR worked closely with Camel Snus retailers to promote their product by requiring display conditions, trained retailers to engage with customers, and provided financial incentives to sell Camel Snus. RJR made it clear that retailers must have refrigerators to display their products, recognizing that refrigeration is a selling point for Camel Snus and an effective method for increasing awareness: 'Refrigerator merchandising [is a] key awareness driver" ${ }^{19}$. Advertising included brochures, signs, and small product displays on retailers' counters. RJR recognized that the cashiers could play a role in increasing awareness, as observed in documents stating: 'Stores that do a better job in explaining the SNUS proposition to Adult Tobacco Users sell more SNUS Tins per week ... SNUS presence at retail generates a lot of curiosity and questions ${ }^{20}$. RJR provided training videos to retailers and other additional items to promote their product: 'This DVD can serve as a quick introduction to SNUS for all clerks in stores with SNUS distribution and reinforces the SNUS proposition ... This button can be worn by clerks at store level to generate awareness ...'21. To determine whether these clerks were properly engaging customers, RJR employees posed as 'Secret Shoppers' to observe the interaction between the clerk and customer. If the clerk successfully promoted Camel Snus to the customer, they were rewarded with a financial incentive (Table $1)^{22}$. Retailers also received other incentives to promote Camel Snus, such as receiving $\$ 0.14$ per tin, $\$ 0.07$ per sleeve, and $\$ 1.26$ per case sold.

\section{Expanding from the primary target population}

The initial target population of Camel Snus was ASU30 males as evidenced by an internal document written 20 February 2006 (Bates: 552397577552397605), which stated: 'ASU30 (primary target) .... ATU30 (secondary, not target)'19. Yet, by December 2006, RJR changed its marketing strategy with a primary focus on male and female ATU30 (smokers) and a secondary focus on adult moist snuff users under the age of 30 years (Bates: 541273328$541273348)^{23}$. RJR was particularly interested in '... these 40 million smokers. The majority of our energy, resource, communications, and engagement will be directed at this group. This group represents our biggest opportunity'24. RJR acknowledged the challenges of expanding the primary target population to female smokers because 'consideration and trial are critical bottlenecks among ATC [adult tobacco consumer] females' ${ }^{25}$; yet, the same document stated that 'Opportunity is evident however, in the behavioral profile similarity between Female and Male Snusers'. RJR has also been investigating ways to reach the Latinx community: 'The general assumption since SNUS was introduced has been that Hispanics ATU won't use oral tobacco ... Gain insights on what benefits of SNUS are relevant to this group, Gain understanding of the main barriers for trial and adoption ... ${ }^{26}$. RJR found that Hispanic ATUs generally have little awareness of oral tobacco, they are not early adopters of tobacco products, and they prefer saltier flavors compared to other ethnic groups ${ }^{26}$. In addition, they found that collectivism predominates individualism in the Latinx culture. Thus, a potential marketing tactic targeting Hispanics was to tailor the message about being able to use Camel Snus at any time without affecting the people with whom they socialize ${ }^{26}$. Lastly, RJR aggressively targeted dual users as evidenced by the statement: 'We will tactically leverage the dual users ...'24. RJR claims that dual users are easy targets because they face significantly less barriers to initiating SLT compared to smokers. For example, '... they don't face the same barriers like smokers ... WHY IS THAT? The answer is obvious ... They already put tobacco in their mouth, They are the early snus adopters: we call them the "low hanging fruit"...24.

\section{Differentiating snus from traditional smokeless tobacco}

RJR emphasized the need that Camel Snus be marketed as a novel and as a different product from 
traditional SLT. First, the company highlighted the Swedish origin of snus via the statement 'Bring the Euro vibe to life and spotlight Camel Snus'27. RJR also used a marketing campaign referred to as the 'Swedish Invasion with Ingas' ${ }^{27}$, illustrated by Swedish women dressed in winter clothing who promote Camel Snus from their limousines, via word-ofmouth (WOM), and at adult only facilities (AOFs). A marketing tactic referred to as 'edutainment' entailed getting the attention of prospective customers and educating them about Camel Snus.

Second, RJR emphasized that Camel Snus differs from traditional SLT in its manufacturing (pasteurization vs fermentation) and the attribute of not requiring expectoration, 'Smokeless/spitting not required $=$ Convenient $/$ Discrete ${ }^{\prime 27}$. Qualitative studies conducted by RJR revealed that consumers were initially unaware that spitting was not required and were subsequently more receptive to using Camel Snus once they were correctly informed about how to use the product ${ }^{27}$. This attribute was key to the success of snus as conveyed by one individual who said: "Interest in trying a "spitless, smokeless" tobacco product and general curiosity about SNUS were the driving forces behind trial ... This positive product experience yielded a strong commitment not only to purchase Camel SNUS in the future but also to recommend it to other tobacco users ... focus on educating tobacco consumers (especially smokers) on the smokeless, spitless and convenience benefits of Camel SNUS ${ }^{28}$.

Third, a key selling point of Camel Snus is that the product is sold and consumed at a low temperature. Unlike other companies that sell SLT, RJR highlighted the freshness of Camel Snus from refrigerating the tobacco: 'Make sure consumers get the idea ... Focus on crystallizing the idea among those at the top of the funnel, using "Sold Cold" as a differentiator .. $.25^{25}$. RJR stated that the freshness of Camel Snus differentiates the product from Marlboro Snus; the latter is '... received comfortably as a traditional tobacco experience, while Camel SNUS is seen as an intriguing, new, innovative way to enjoy tobacco ... Fuel this positioning point of difference ... ${ }^{29}$. To ensure that their products are always refrigerated, RJR only accepts retailers equipped with adequate refrigeration. If retailers do not have the necessary refrigerators, RJR rents them alongside with other promotional materials.

\section{A shift in marketing messages}

RJR shifted its marketing messages in 2009 from promoting the practical benefits of using Camel Snus to focusing more on the emotional benefits of using the product. RJR initially used the 'Snus Friendly Series' to promote the 'spit-free', refreshing, and cold characteristics of Camel Snus. Once the practical benefits of using Camel Snus were perceived by smokers and SLT users, RJR shifted its messaging to an emotional appeal (Table 1$)^{30}$. Freedom was a hallmark characteristic of RJR's new messaging for Camel Snus in the 'Break Free' advertisements, which encouraged users to break from the norm: 'At Camel, we believe in the freedom of creating your own path ... We believe in treating bold, original experiences that free you to enjoy tobacco on your own terms. Last we checked, it's the American way' ${ }^{30}$. RJR built its messaging on this nuance of freedom and breaking free from societal norms to create an image of fun, excitement, and novelty (Table 1$)^{30}$. The message of breaking from convention appears to promote Camel Snus as a new way for smokers to enjoy tobacco without having to compromise: 'Position Camel SNUS as new, fun way to experience tobacco pleasure ....31. In addition, the emotional messaging appeals to potential new targets as exemplified by the statement: 'Speak to ATC Females with Evocative Voice. Consideration and Trial are critical bottlenecks among ATC Females ... Cultivate their interest with a tone and messages more relevant to their lifestyles and emotional needs' ${ }^{25}$. Although it was unclear to which specific societal norms or freedoms the 'Break Free' messages were referring to, the messaging was most likely intended to promote Camel Snus as a situational substitute as evidenced by the quote: 'Shift from convenience to the freedom to make any "when I can't smoke" moments more pleasurable ${ }^{32}$.

\section{DISCUSSION}

This study has revealed that RJR used third parties for marketing, changed its target population, differentiated snus from traditional SLT, and used the 'Break Free' messages to promote Camel Snus. Furthermore, RJR borrowed marketing strategies from Skoal Bandits as evidenced by promoting the 'spit-free' aspect of SLT; targeting micro-markets (e.g. Latinx); and using company representatives (e.g. 'Secret Shoppers') to promote their product. 
RJR's use of third parties to promote Camel Snus, instead of RJR employees, was an attempt to bypass previous tobacco control laws. Before the TCA, tobacco employees were not allowed to directly hand out tobacco samples in public, and free samples could only be distributed when accompanied with a verified purchase of tobacco products at retail stores $^{33}$. However, by using third parties, free samples could be distributed to others without any barriers. With the enactment of the TCA, all free SLT products can now only be distributed in qualified adult-only facilities ${ }^{33}$. While tobacco retailers are not permitted to distribute free samples, they can make harm reduction claims as a way of promoting the product. Creating an environment where snus is perceived as less harmful may make potential customers less reluctant to try snus. In fact, US young adults who perceived snus to be less harmful than cigarettes were significantly much more likely to initiate snus ${ }^{34}$. In the past, the USST only used company representatives to promote Skoal Bandits to educate the public about the benefits of using pouches instead of loose tobacco ${ }^{4}$. In contrast, RJR has been shown to promote Camel Snus by using outside advocacy groups.

Our analysis has also revealed that RJR targeted new demographic populations and shifted their attention from SLT users in 2006 to smokers and dual tobacco users in 2009. Although the reason for this change was not explicitly stated in the documents, the targeting of both smokers and dual users is likely intended to encourage dual use or switch dual users' preferences. This is supported by other studies indicating Camel Snus was advertised in places where smoking is prohibited, which likely encourages use of the product in such places ${ }^{5}$. This is concerning as dual use of tobacco products may lead to increased risk for oral and pharyngeal cancers in addition to smoking-related health outcomes, despite snus having fewer health risks ${ }^{11}$. It was not unexpected that statements indicating RJR's explicit intent of targeting smokers and dual users were not found, given the admonition by one RJR representative: '... Nothing is ever, over off the record. Speak as if your comments will appear on the front page of USA Today tomorrow morning. ${ }^{35}$. RJR initially mimicked USST's attempt to target micro-markets for Skoal Bandits in the late 80s and
$90 \mathrm{~s}^{4}$; yet RJR switched its focus from SLT users to smokers and dual users. Our results also indicate that a key marketing strategy used to promote Camel Snus is to differentiate itself from traditional SLT from other major competitors (i.e. exoticism of the European origin of snus). This confirms previous studies emphasizing the European exoticism as a marketing strategy for Camel Snus ${ }^{4}$.

Camel Snus shifted from promoting the practical benefits of using snus to using ambiguous messages known as the 'Break Free' movement, which consisted of cryptic messages asking users to break from societal norms and to pursue freedom. Although the true meaning behind these messages and the intentions of why RJR has made this change has not been found, the messaging behind 'Breaking Free' most likely encourages the use of Camel Snus as a situational substitute ${ }^{32}$. RJR's initial promotion of the practical benefits of using SLT appears to reflect USST's marketing of Skoal Bandits, which promoted use of the 'spit-free' product as a situational substitute for smokers ${ }^{4}$. This aligns with our investigation as RJR initially promoted the "spitfree' characteristic of Camel Snus but later used the 'Break Free' messages to promote the product.

RJR's recruitment of dual users as snus ambassadors, a group that is unlikely to be receptive to harm reduction, has not been reported previously. Although our investigation did not find any documents that explicitly outlined RJR's underlying intentions of recruiting these dual users, such recruitment is problematic from a public health perspective because poly-tobacco users are not an ideal group for promoting harm reduction. Despite the small percentage of the US population (3.6\%) that uses SLT, approximately half are poly-tobacco users (data from 2012-2014) ${ }^{36}$. As previously mentioned, dual usage may lead to additive risks from smoking and may cause more harm at the population level ${ }^{8-11}$. Furthermore, the recruitment of dual users to promote SLT indirectly supports the notion that US tobacco companies may be taking advantage of Sweden's success to promote Camel Snus as a situational substitute instead of a permanent replacement, which has been a concern for several tobacco control activists ${ }^{1,2,8}$. Advocates for snus may overlook the potential of increased dual users in the US, and thus should consider the 
consequences of promoting dual usage. Regardless of the current policies of the TCA and FDA, snus advocates may continue to make harm reduction claims through word-of-mouth and social media. In fact, snus advocates promote SLT use on popular internet communities, such as YouTube and Reddit. It is not apparent, however, if these advocates are tied to RJR.

The recruitment of advocates parallels the tobacco industry's recruitment of African American communities to promote the sales of menthol cigarettes and advocate against anti-smoking policies $^{37,38}$. Internal documents revealed that their underlying intentions of creating these ties was to create a positive brand identity, create a new untapped market for menthol cigarettes, and exploit the communities to help advocate against antitobacco laws ${ }^{37}$. Consequently, African Americans have the highest menthol smoking rates among others $^{39}$. RJR may be repeating this strategy with dual users by creating a more positive image through the promotion of the less harmful properties of SLT; expanding the market for SLT among smokers and SLT users; and creating an advocacy group against anti-tobacco policies (e.g. rescinding the restriction of harm reduction claims on SLT products).

\section{Strengths and limitations}

There are potential limitations to this study that need to be considered. First, not all relevant documents were available because the internal documents containing personal information or company patents were retracted. Second, RJR was probably cautious in disclosing any questionable intent or marketing practices since the company was required to release the internal documents as stipulated by the 1998 Master Settlement Agreement ${ }^{35}$. Third, additional internal documents related to our investigation, which were created in 2005-2009, could potentially be released at a later time. However, our research team is confident that data saturation was achieved as further investigation of documents did not yield new codes or themes in the latter half of the analysis. Fourth, interrater reliability scores between coders were in the lower 'substantial' range ${ }^{15}$. However, these codes are only used to help guide the development of themes. Despite these limitations, our investigation was able to confirm the results from previous marketing studies on Camel Snus ${ }^{1,4}$. Most previous content analyses on the marketing of Camel Snus used publicly available advertisements. Analyzing industry documents provides more certainty and less speculation in interpreting the results. For example, our findings show that RJR explicitly targeted new demographic groups that differ from traditional SLT users, such as women, the Latinx community, and dual users. Content analyses investigating industry documents are recognized by researchers as effective methods to identify the industry's strategies on marketing tobacco products and targeting communities ${ }^{40}$. For example, identified marketing strategies used to target specific populations could be used against the tobacco industry by employing creative ways to counter-market tobacco products $^{40}$. In fact, revealing the tobacco industry's underlying intentions via internal documents has been an effective measure in reducing the uptake of cigarettes in younger populations ${ }^{41}$. The present study encourages further investigation on the extent of the use of third-party groups promoting SLT, which could assist tobacco control efforts in the US.

\section{CONCLUSIONS}

The findings reveal that RJR intended to market Camel Snus to non-users of SLT and dual users. Furthermore, RJR employed creative marketing tactics using dual tobacco users and tobacco retailers to promote the sales of Camel Snus, a finding not reported previously. This strategy implies that Camel Snus was not primarily intended as a cigarette replacement, despite RJR's expressed commitment to harm reduction. Furthermore, third parties and retailers may have been used to promote snus in ways which bypass US federal law. The present study encourages tobacco control advocates to monitor the use of third parties for marketing tobacco products.

\section{REFERENCES}

1. Mejia AB, Ling PM. Tobacco industry consumer research on smokeless tobacco users and product development. Am J Public Health. 2010;100(1):78-87. doi:10.2105/AJPH.2008.152603

2. Timberlake DS, Pechmann C, Tran SY, Au V. A content analysis of Camel Snus advertisements in print media. Nicotine Tob Res. 2011;13(6):431-439. doi:10.1093/ntr/ntr020

3. Carpenter CM, Connolly GN, Ayo-Yusuf OA, Wayne GF. Developing smokeless tobacco products for smokers: an examination of tobacco industry documents. Tob Control. 2009;18(1):54-59. doi:10.1136/tc.2008.026583 
4. Hendlin YH, Veffer JR, Lewis MJ, Ling PM. Beyond the brotherhood: Skoal Bandits' role in the evolution of marketing moist smokeless tobacco pouches. Tob Induc Dis. Tob Induc Dis. 2017;15(December):1-11. doi:10.1186/s12971-017-0150-y

5. Rogers JD, Biener L, Clark PI. Test marketing of new smokeless tobacco products in four US cities. Nicotine Tob Res. 2010;12(1):69-72. doi:10.1093/ntr/ntp166

6. Biener L, Roman AM, Mc Inerney SA, et al. Snus use and rejection in the USA. Tob Control. 2016;25(4):386-392. doi:10.1136/tobaccocontrol-2013-051342

7. Curry LE, Pederson LL, Stryker JE. The changing marketing of smokeless tobacco in magazine advertisements. Nicotine Tob Res. 2011;13(7):540-547. doi:10.1093/ntr/ntr038

8. Wetter DW, McClure JB, De Moor C, et al. Concomitant use of cigarettes and smokeless tobacco: prevalence, correlates, and predictors of tobacco cessation. Am J Prev Med. 2003;34(6):638-648. doi:10.1006/pmed.2002.1032

9. Timberlake DS. A latent class analysis of nicotine-dependence criteria and use of alternate tobacco. J Stud Alcohol Drugs. 2008;69(5):709-717. doi:10.15288/jsad.2008.69.709

10. Post A, Gilljam H, Rosendahl I, Bremberg S, Galanti MR. Symptoms of nicotine dependence in a cohort of Swedish youths: a comparison between smokers, smokeless tobacco users and udal tobacco users. Addiction. 2010;105(4):740746. doi:10.1111/j.1360-0443.2009.02852.x

11. Roosaar A, Johansson AL, Sandborgh-Englund G, Axéll T, Nyrén O. Cancer and mortality among users and nonusers of snus. Int J Cancer. 2008;123(1):168-173. doi:10.1002/ijc.23469

12. Goodman LA. Snowball sampling. Ann Stat. 1961;32(1):148-170. doi:10.1214/aoms/1177705148

13. Gale NK, Heath G, Cameron E, Rashid S, Redwood S. Using the framework method for the analysis of qualitative data in multi-disciplinary health research. BMC Med Res Methodol. 2013;13(1):117. doi:10.1186/1471-2288-13-117

14. R. J. Reynolds. U.S. Smokeless Overview. In: UCSF Library RJ Reynolds Records. https://www.industrydocumentslibrary. ucsf.edu/tobacco/docs/zjxl0223. Published 2009. Accessed December 18, 2020.

15. McHugh ML. Interrater reliability: the kappa statistic. Biochem Med (Zagreb). 2012;22(3):276-282. PMID:23092060.

16. ATLAS.ti [computer program]. Version 8.4. Berlin, Germany: Scientific Software Development GmbH; 2013.

17. Caroll D, R. J. Reynolds. Camel Snus Trier Callback Research. In: UCSF Library RJ Reynolds Records. https:// www.industrydocumentslibrary.ucsf.edu/tobacco/docs/ sfpk0222. Published 2007. Accessed December 18, 2020.

18. R. J. Reynolds. Camel Snus - Wave II Awareness/Trial/ Purchase Study Launch/Expansion Market Results. In: UCSF Library RJ Reynolds Records. https://www. industrydocumentslibrary.ucsf.edu/tobacco/docs/tkfm0222. Published August 2008. Accessed December 18, 2020.

19. R. J. Reynolds. Introducing... Camel Snus. In:
UCSF Library RJ Reynolds Records. https://www. industrydocumentslibrary.ucsf.edu/tobacco/docs/ ygpj0222. Published 2006. Accessed December 18, 2020.

20. R. J. Reynolds. Camel Snus Markets Customer Education Programs. In: UCSF Library RJ Reynolds Records. https://www.industrydocumentslibrary.ucsf.edu/ tobacco/docs/rtxf0222. Published March 26, 2008. Accessed December 18, 2020.

21. R. J. Reynolds. Snus Customer Education Programs. In: UCSF Library RJ Reynolds Records. https://www. industrydocumentslibrary.ucsf.edu/tobacco/docs/ tllm0222. Published March 26, 2008. Accessed December $18,2020$.

22. R. J. Reynolds. Snus Revitalization/Education Funds. Results - Snus Secret Shoppers Indiana. In: UCSF Library RJ Reynolds Records. https://www. industrydocumentslibrary.ucsf.edu/tobacco/docs/ htd10225. Published September 11, 2008. Accessed December 18, 2020.

23. R. J. Reynolds. Camel Snus 2006 (20060000) Final Media Plan. In: UCSF Library RJ Reynolds Records. https:// www.industrydocumentslibrary.ucsf.edu/tobacco/docs/ ythp0221. Published December 15, 2006. Updated January 4, 2007. Accessed December 18, 2020.

24. R. J. Reynolds. SNUS. "5Ps". In: UCSF Library RJ Reynolds Records. https://www.industrydocuments.ucsf. edu/tobacco/docs/rsyl0222. Published March 30, 2009. Accessed December 18, 2020.

25. R. J. Reynolds. Camel Snus Macro Insights. In: UCSF Library RJ Reynolds Records. https://www. industrydocumentslibrary.ucsf.edu/tobacco/docs/yjkx0225. Published August 1, 2009. Accessed December 18, 2020.

26. R. J. Reynolds. Camel Snus Among Hispanics. In: UCSF Library RJ Reynolds Records. https://www. industrydocumentslibrary.ucsf.edu/tobacco/docs/srbl0222. Published June 2009. Updated July 2009. Accessed December 18, 2020.

27. R. J. Reynolds. Training Map. Camel Snus. In: UCSF Library RJ Reynolds Records. https://www. industrydocumentslibrary.ucsf.edu/tobacco/docs/tfdl0223. Published March 4, 2008. Accessed December 18, 2020.

28. R. J. Reynolds. Create the Future. Lead the Movement. Camel Snus Military Buyer Study. In: UCSF Library RJ Reynolds Records. https://www.industrydocuments.ucsf. edu/tobacco/docs/lhxm0222. Published August 2008. Updated June 16, 2009. Accessed December 18, 2020.

29. R. J. Reynolds. Snus. Arizona Groups: Camel Snus vs. Marlboro Snus. Executive Summary of Findings April 2009 (20090400). In: UCSF Library RJ Reynolds Records. https://www.industrydocumentslibrary.ucsf. edu/tobacco/docs/xxgm0222. Published April 2009. Accessed December 18, 2020.

30. R. J. Reynolds. Camel Snus. In: UCSF Library RJ Reynolds Records. https://www.industrydocumentslibrary.ucsf. edu/tobacco/docs/kygm0222. Published May 17, 2009. 
Accessed December 18, 2020.

31. R. J. Reynolds. Innovations Business Unit 2006 (20060000). In: UCSF Library RJ Reynolds Records. https://www.industrydocumentslibrary.ucsf.edu/ tobacco/docs/gzhj0222. Published October 18, 2005. Accessed December 18, 2020.

32. R. J. Reynolds. CAMEL SNUS UPDATE. In: UCSF Library RJ Reynolds Records. https://www.industrydocumentslibrary. ucsf.edu/tobacco/docs/kygm0222. Published May 17, 2009. Accessed December 18, 2020.

33. Federal Drug Administration. Family Smoking Prevention and Tobacco Control Act - An Overview. https://www.fda. gov/tobacco-products/rules-regulations-and-guidance/ family-smoking-prevention-and-tobacco-control-actoverview. Updated June 3, 2020. Accessed July 21, 2020.

34. Choi K, Forster J. Awareness, perceptions and use of snus among young adults from the upper Midwest region of the USA. Tob Control. 2013;22(6):412-417. doi:10.1136/tobaccocontrol-2011-050383

35. R. J. Reynolds. Camel Snus Rules of the Road: When it Comes to Talking with the News Media. In: UCSF Library RJ Reynolds Records. https://www.industrydocuments. ucsf.edu/tobacco/docs/ljpf0222. Published March 20, 2006. Accessed December 18, 2020.

36. Sung HY, Wang Y, Yao T, Lightwood J, Max W. Polytobacco use and nicotine dependence symptoms among US adults, 2012-2014. Nicotine Tob Res. 2018;22(Suppl 1):S88-S98. doi:10.1093/ntr/nty050

37. Yerger VB, Malone RE. African American leadership groups: smoking with the enemy. Tob Control. 2002;11(4):336-345. doi:10.1136/tc.11.4.336

38. Gardiner PS. The African Americanization of menthol cigarette use in the United States. Nicotine Tob Res. 2004;6(Suppl 1):S55-S65. doi:10.1080/14622200310001649478

39. Stahre M, Okuyemi KS, Joseph AM, Fu SS. Racial/ethnic differences in menthol cigarette smoking, population quit ratios and utilization of evidence-based tobacco cessation treatments. Addiction. 2010;105:75-83. doi:10.1111/j.1360-0443.2010.03200.x

40. Balbach ED, Gasior RJ, Barbeau EM. RJ Reynold's targeting of African Americans: 1988-2000. Am J Public Health. 2003;93(5):822-827. doi:10.2105/ajph.93.5.822

41. Bauer UE, Johnson TM, Hopkins RS, Brooks RG. Changes in youth cigarette use and intentions following implementation of a tobacco control program: findings from the Florida Youth Tobacco Survey. JAMA. 2000;284(6):723-728. doi:10.1001/jama.284.6.723

42. R. J. Reynolds. Camel Snus Website. Print Version. In: UCSF Library RJ Reynolds Records. https://www. industrydocumentslibrary.ucsf.edu/tobacco/docs/hpxp0221. Published May 1, 2009. Accessed December 18, 2020.

43. R. J. Reynolds. Camel Snus Update. In: UCSF Library RJ Reynolds Records. Retrieved from https://www. industrydocuments.ucsf.edu/docs/\#id=ykdg0226. Published June 1, 2009. Accessed December 18, 2020.
44. R. J. Reynolds. Snus Hispanic. In: UCSF Library RJ Reynolds Records. https://www.industrydocuments. ucsf.edu/docs/\#id=yglx0225. Published July 29, 2009. Accessed December 18, 2020.

45. R. J. Reynolds. Village Pantry Manager Meeting. In: UCSF Library RJ Reynolds Records. https://www. industrydocumentslibrary.ucsf.edu/tobacco/docs/ zshm0222. Published May 28, 2009. Updated June 12, 2009. Accessed December 18, 2020.

\section{CONFLICTS OF INTEREST}

The authors have completed and submitted the ICMJE Form for Disclosure of Potential Conflicts of Interest and none was reported.

\section{FUNDING}

There was no source of funding for this research.

PROVENANCE AND PEER REVIEW

Not commissioned; externally peer reviewed. 